\title{
Modelling of Wind Turbine Operation for Enhanced Power Electronics Reliability
}

DOI:

10.1109/TEC.2022.3144499

\section{Document Version}

Accepted author manuscript

Link to publication record in Manchester Research Explorer

\section{Citation for published version (APA):}

Ahmedi, A., Barnes, M., Levi, V., Carmona Sanchez, J., Ng, C., \& Mckeever, P. (2022). Modelling of Wind Turbine Operation for Enhanced Power Electronics Reliability. IEEE Transactions on Energy Conversion, 37(3), 17641776. https://doi.org/10.1109/TEC.2022.3144499

\section{Published in:}

IEEE Transactions on Energy Conversion

\section{Citing this paper}

Please note that where the full-text provided on Manchester Research Explorer is the Author Accepted Manuscript or Proof version this may differ from the final Published version. If citing, it is advised that you check and use the publisher's definitive version.

\section{General rights}

Copyright and moral rights for the publications made accessible in the Research Explorer are retained by the authors and/or other copyright owners and it is a condition of accessing publications that users recognise and abide by the legal requirements associated with these rights.

\section{Takedown policy}

If you believe that this document breaches copyright please refer to the University of Manchester's Takedown Procedures [http://man.ac.uk/04Y6Bo] or contact uml.scholarlycommunications@manchester.ac.uk providing relevant details, so we can investigate your claim.

\section{OPEN ACCESS}




\title{
Modelling of Wind Turbine Operation for Enhanced Power Electronics Reliability
}

\author{
Arsim Ahmedi, Student Member, IEEE, Mike Barnes, Senior Member, IEEE, \\ Victor Levi, Senior Member, IEEE, Jesus Carmona Sanchez, Chong Ng, Paul McKeever
}

\begin{abstract}
Enhancing power electronics (PE) converter reliability is crucial for ensuring a reliable operation of current and future operating Wind Turbines (WTs). Achieving high reliability of variable speed WT PE systems requires careful consideration of their operation, and particularly their thermal cycling. This paper presents a methodology for evaluating and reconsidering operational strategies of WTs with relation to the thermal loading and lifetime consumption of the converter. The methodology is applied to compare control strategies for the WT generator and evaluate their impact on the converter reliability by observation of the thermal cycles and by calculating the resultant lifetime consumption of those stress cycles. The thermal stress on both the Machine Side Converter (MSC) and the Grid Side Converter (GSC) is examined and compared. It is shown that the least reliable of the three evaluated control strategies is the one that tracks the power curve below rated speed most closely. This paper suggests that dynamic transients associated with the WT control largely influence the IGBT module wear-out and their modelling needs to be prioritized for lifetime studies. These dynamic transients are captured by the improved model whose value is confirmed for the comparisons in the case study of the paper.
\end{abstract}

Index Terms-- Wind Turbine Reliability, Thermal Cycling, Lifetime Estimation, Wear Out, Power Electronics, Converter Reliability

\section{INTRODUCTION}

$\mathrm{W}$ IND energy has a major role in world's energy transition towards the goal of reaching net zero greenhouse emissions by 2050 [1], [2]. A record new wind capacity of $93 \mathrm{GW}$ was installed in 2020, bringing the total capacity to $743 \mathrm{GW}$ [2]. Annual installation numbers are expected to keep increasing and the global cumulative capacity is expected to surpass 1 TW before 2025 [2]. However, this growth also comes with an increased pressure on wind power systems: the need for very high reliability in order to ensure low downtime, high availability and energy production, as well as adequacy and security of energy supply in the power network. To help enable this, there is a need for models which provide information about the system operation and in combination with algorithms investigate scenarios that are likely to lead to failures of the system and its subassemblies [3]-[6].

A. Ahmedi, M. Barnes, Victor Levi, and J. Carmona-Sanchez are with the Department of Electrical and Electronic Engineering, The University of Manchester, Manchester M13 9PL , U.K. (e-mails: arsim.ahmedi@manchester.ac.uk; mike.barnes@manchester.ac.uk; victor.levi@manchester.ac.uk; info@jecasa-ltd.com).

C. Ng and P. McKeever are with The Offshore Renewable Energy Catapult, Glasgow G1 1RD, UK (e-mails: chong.ng@ore.catapult.org.uk; paul.mckeever@ore.catapult.org.uk).
Previous models and research on converter reliability have recognized thermal cycling as the dominating failure mechanism for IGBT power modules [7]-[13]. Thermal stressors and cycling are considered as the most critical failure cause by the industry too [4], [14]. Thermal cycling is the cause for one of the most studied failure modes for IGBT power modules: the bond-wire lift-off failure mode [15]. There are established practices for the evaluation of lifetime based on this failure mode, but there exists a level of ambiguity in mapping the operational root-causes to the failure mechanism [9], [15]. In previous research, different approaches have been used to account for the higher resolution thermal transients while also looking at a substantial period of WT operation when estimating thermal loading and lifetime consumption [9], [16], [17]. Some operational aspects have been included as part of the mission profile. However, in order to run yearly analysis and manage the computational burden, there is a high level of approximation adopted by most approaches. Thus, any transient impact of the turbine control or operation is commonly neglected, apart from wind speed input turbulence which may be included in some cases.

Better modelling and revision of the approaches that are used to understand the problem of estimating PE reliability in WTs are needed. Limitations and possible inaccuracies by current established practices in research are discussed in [18]. One of the conclusions is that any filtering of transients in the mission profile can lead to misinterpretation of consumed lifetime for IGBT modules. The need for improved modelling is also suggested by reliability data for an extensive fleet of modern operating WTs in [19], [20], where the authors argue that some of the observed failure rates are not aligned with what standard and fairly straightforward models would suggest. Access to similar reliability data to support the modelling is limited because of commercial sensitivity as well as the unprecedented pace of change of the technology, which means that some data from reliability surveys are not representative of more recently deployed technology. Accurate model representation will thus remain an important component in de-risking future WT technology, and therefore improving these models is of high interest.

Thermal loading for DFIG dynamic response has been modelled in [11] where the region of operation around synchronous speed is identified to be the least reliable region of operation. A similar machine and solution have been studied in [7] where a controller adjustment to mitigate large thermal cycling has been suggested. Both of these studies have confirmed that there is a potential for further improvement of converter reliability with finding root causes of stress in the operation of the WT and 
making proper adjustments to mitigate those conditions.

Converter reliability assessment of a direct-drive PMSG system has been undertaken in [21]. This study has considered both long-term power cycling and short term (fundamental frequency) cycling, but only for steady-state WT operation using the wind speed probability distribution instead of the actual unfiltered wind speed profile. To the authors' knowledge, there is no previous work that has provided a full approach for PE reliability enhancements of fully-rated converter WTs while investigating the relevance of the system-level operational and control transients as undertaken in the rest of this paper. Here, some of the lifetime estimation principles used by previous work have been adjusted and applied in combination with a specific operational model of a WT adapted from the NREL baseline 5MW WT [22]. The effects that operational aspects of different control design can have on converter reliability are analyzed. Additionally, the difference in lifetime results for the MSC and GSC, which operate in rectifier and inverter mode respectively, is also shown.

The main contribution of the work in this paper can be summarized as follows:

- Proposal of an augmented methodology for lifetime estimation of WT IGBT modules. Compared to previous approaches, this methodology advances the mission profile consideration and focuses on the WT operation where root causes for some of the largest temperature stress in the converter can be found. For this intention, an extra level of model complexity is added. This improvement provides pronounced potential for reliability enhancements using WT and converter control features.

- The application and usefulness of the methodology are demonstrated by the comparisons and case study in the paper. First, the value of using more detailed WT modelling and time-series wind profile data for this kind of analysis is confirmed: the largest thermal cycling (stress) in the converter is a result of the WT transients, which are ignored by models that apply a yearly wind distribution with simplified steady-state analysis. Moreover, the case study is used to produce reliability information and conclusions for different WT operational aspects, mainly the comparison of thermal stress and lifetime consumption for widely-used WT control strategies, as well as the machine side and the grid side converter design and control modes (rectifier and inverter).

The paper is organized as follows: in section 2, the structure of the modelling methodology for quantifying lifetime consumption is introduced. In section 3, the relevant control aspects of the WT, generator, and the two converters are discussed. In section 4, the model is run at WT rated wind speed and the steady-state evaluation of the thermal-loss model is shown. Finally, in section 5, the WT model is run with turbulent wind data and different control scenarios are compared in terms of thermal stress and lifetime consumption. The conclusions and main insights from the analysis are discussed in section VI.

\section{DESCRIPTION OF THE METHODOLOGY}

An overview of the approach that is used in this paper for linking the transient changes in the WT operational system to the converter thermal loading, and calculating the consumed lifetime for the IGBT power module, is shown in Fig. 1. Unlike previous approaches, in this paper a higher focus is placed on the first layer, the WT Operational Model: it is assessed how the changes in this level are reflected in the other two levels, the converter thermal stress and its lifetime consumption. This unlocks an opportunity to identify root causes of major failure contributors and thus contribute to reliability and thermal fatigue improvements. In Fig. 1, the full line arrows indicate connection/dependency in the time-series models and dashed lines indicate information flow. In the following subsections, the underlying structure of each of the three distinct layers forming this approach is briefly introduced.

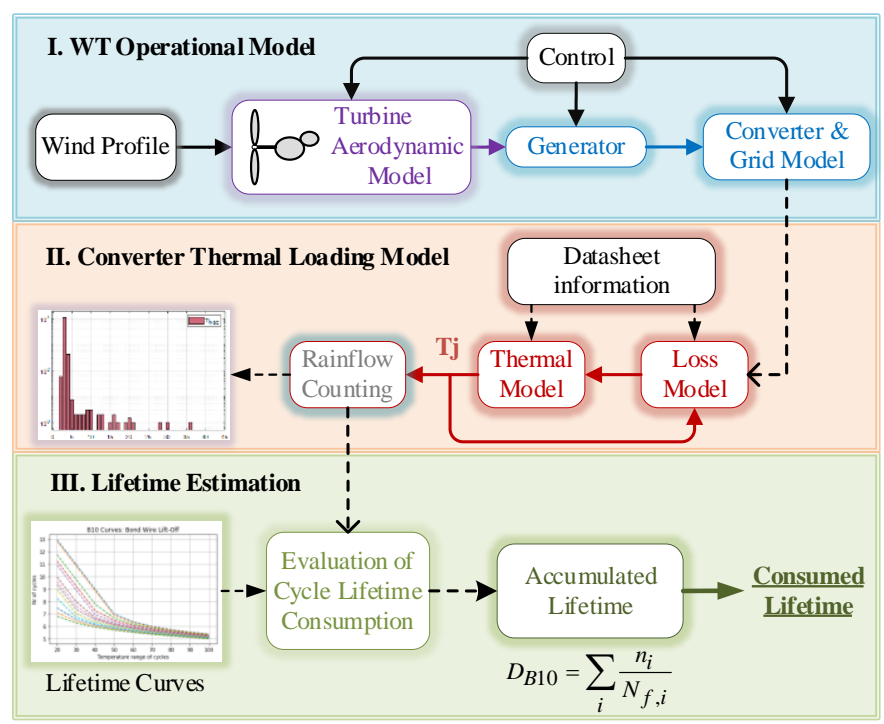

Fig. 1. Structure of the methodology for calculating converter consumed lifetime with dependence on control and operational transients of the WT.

\section{A. WT Operational Model}

The WT configuration modelled in the analysis is the NREL baseline 5 MW WT [22] that has been adapted for a direct-drive application [23]. The elimination of the gearbox is preferred for offshore WTs because it is susceptible to a high failure rate, contribution to downtime, and maintenance issues [24]. The generator is a PMSG with electrical parameters adapted from [25]. The converter is a theoretical design: 5SNA 0400J650100 ABB HiPak modules [26] which are connected in series and parallel to match the power and voltage ratings in a two-level VSC configuration. The thermal and lifetime analysis is done on one of these IGBT modules. The two-level VSC was chosen for simplification of the control at the switching-device level, which is not the focus of the model here. PWM switching frequency events are too fast to impose any lifetime-significant thermal cycling and are not modelled. More details for thermal and lifetime analysis for a three-level NPC can be found in references [9], [27]. Technical and theoretical aspects have been respected in adapting and constructing the whole WT and converter system, however since industrial practice is commercially sensitive and not always public, sometimes the model may vary from industrial design. Nevertheless, the aim of this work is not converter design. The topology in this paper has 
been carefully selected and the aspects that are being compared are in line with industrial practice of current and planned operating WTs - therefore, the conclusions and contributions are valid for the intended analysis and applicable to the majority of standard WTs. Moreover, to assess the reliability of more specific aspects of various WT system designs, the model can be modified, with added detail as necessary.

The WT operational model is a time-series model that has been built in MATLAB/SIMULINK. It consists of an analytical turbine-aerodynamics representation and a mechanical model, which are based on (1)-(6) and (7)-(9). The kinetic power of the wind $P_{k}[\mathrm{~W}]$, given in (1), is proportional to the air density $\rho$ $\left[\mathrm{kg} / \mathrm{m}^{3}\right]$, turbine swept area $A\left[\mathrm{~m}^{2}\right]$ and wind speed $v_{w}[\mathrm{~m} / \mathrm{s}]$. As given in (2), the WT extracted power $P_{w}$ is related to $P_{k}$ through the power coefficient $C_{p}$, which is defined by (3)-(4) and is related to the blade pitch angle $\beta$ and the tip-speed ratio $\lambda$. The tip-speed ratio is given in (5), where $l[\mathrm{~m}]$ is the blade length and $\omega_{w}[\mathrm{rad} / \mathrm{s}]$ is the turbine angular speed. The WT torque is given with the expression in (6) [28], [29].

$$
\begin{gathered}
P_{k}=\frac{1}{2} \rho A v_{w}{ }^{3} \\
P_{w}=P_{k} C_{p}=\frac{1}{2} \rho \pi l^{2} v_{w}{ }^{3} C_{p} \\
C_{p}=0.5176\left(\frac{116}{\lambda_{i}}-0.4 \beta-5\right) e^{\frac{-21}{\lambda_{i}}}+0.0068 \lambda \\
\frac{1}{\lambda_{i}}=\frac{1}{\lambda+0.008 \beta}-\frac{0.035}{\beta^{3}+1} \\
\lambda=\frac{l \omega_{w}}{v_{w}} \\
T_{w}=\frac{1}{2 \omega_{w}} \rho \pi l^{2} v_{w}{ }^{3} C_{p}
\end{gathered}
$$

The mechanical drivetrain model in torque equations (7)-(9) is a two-mass model which provides the necessary level of fidelity for the transients and dynamics of interest [29]. With $w$ and $g$ subscripts are referred the WT and generator quantities respectively: $J$ is the moment of inertia, $k_{w g}$ and $d_{w g}$ are the shaft mutual stiffness and damping, $\theta$ is the shaft angle. These WT specific parameters, most notably the moment of inertia for the turbine and generator, are important when designing the control which is considered in this paper: because they affect the response of the generator to wind speed changes, as well as the converter current transients to impose such response, they are reflected in the thermal stress of the converter as well.

$$
\begin{gathered}
J_{w} \frac{d \omega_{w}}{d t}=T_{w}-k_{w g} \theta_{w g}-d_{w g} \frac{d \theta_{w g}}{d t} \\
J_{g} \frac{d \omega_{g m}}{d t}=k_{w g} \theta_{w g}+d_{w g} \frac{d \theta_{w g}}{d t}-T_{g} \\
\frac{d \theta_{w g}}{d t}=\omega_{w}-\omega_{g m}
\end{gathered}
$$

\section{B. Converter Thermal Loading Model}

The thermal stress of the converter chips (IGBT and diode) is impacted by changes in external (ambient) temperature as well as the internal losses and power cycling generated from the current through the device [4]. The thermal stress that can be directly correlated to the turbine operation dynamics and the mission profile is a consequence of the losses generated inside the device. Therefore, the main part of the converter loading model applied here consists of calculating the losses in the IGBT and diode chips. After calculating the losses, to obtain the temperature change, the thermal network for one module connected to its heatsink is considered. The temperature change of the ambient is added to the analysis using superposition.

Conduction losses of the IGBT/diode are defined with (10), where $I_{c}$ is the current through the chip, and $k_{0}, k_{1}, m_{0}, m_{1}$, are coefficients used to implement temperature-dependent calculation of losses using curve fitting of datasheet information [30].

$$
P_{c o n}\left(I_{c}, T_{j}\right)=\overbrace{\left(k_{0}+k_{1} \cdot T_{j}\right)}^{V_{C E 0}\left(T_{j}\right)} \cdot I_{c}+\overbrace{\left(m_{0}+m_{1} \cdot T_{j}\right)}^{r_{C E}\left(T_{j}\right)} \cdot I_{c}^{2}
$$

With (10) are given the instantaneous power losses of the chip as a function of the current. Using (10), the average conduction losses of the IGBT can be derived with the integration in (11).

$$
P_{c o n d, a v, I G B T}=\frac{1}{T_{0}} \int_{0}^{T_{0} / 2}\left(P_{c o n}\left(I_{c}, T_{j}\right) \cdot \tau(t)\right) d t
$$

If the current $I_{c}$ is given with (12), then for inverter operation the duty-variation (PWM pulse pattern) of the IGBT - if a suitably fast switching frequency is assumed - can be written as (13) [31].

$$
\begin{gathered}
I_{c}(t)=\hat{\mathrm{I}}_{c} \sin (\omega t) \\
\tau(t)=\frac{1}{2}(1+m \sin (\omega t+\varphi))
\end{gathered}
$$

In (13), $m$ is the modulation index and $\varphi$ is the angle between the current phasor and synthetized voltage phasor. Combining (11)-(13) and performing the integration, the expression (14) for the IGBT conduction losses is derived.

$$
\begin{aligned}
& P_{\mathrm{av}, \text { cond }}\left(T_{j}\right)=\frac{1}{2}\left(V_{\mathrm{CE} 0}\left(T_{j}\right) \cdot \frac{\hat{\mathrm{I}}_{\mathrm{c}}}{\pi}+r_{\mathrm{CE} 0}\left(T_{j}\right) \cdot \frac{\hat{\mathrm{I}} \mathrm{c}^{2}}{4}\right)+ \\
& +m \cdot \cos \varphi \cdot\left(V_{\mathrm{CE} 0}\left(T_{j}\right) \cdot \frac{\hat{\mathrm{I}}_{\mathrm{c}}}{8}+\frac{1}{3 \pi} \cdot r_{\mathrm{CE} 0}\left(T_{j}\right) \cdot \hat{\mathrm{I}}_{\mathrm{c}}{ }^{2}\right)
\end{aligned}
$$

Switching and reverse recovery losses, for the IGBT and diode respectively, are given in (15) and (16), where with ref are indexed the reference values for the given datasheet information; $K_{v 1}$ and $K_{v 2}$ are factors for scaling to the operating voltage. With the constants $K_{T, S w}$, and $K_{T, r r}$ the junction temperature $T_{j}$ dependence of the switching losses is added [32].

$$
\begin{aligned}
E_{o n+o f f} & =E_{o n+o f f}^{r e f} \cdot\left(\frac{V_{c c}}{V_{c c}^{r c e f}}\right)^{K_{v 1}} \cdot\left(1+K_{T, s w} \cdot\left(T_{j}-T_{j}^{r e f}\right)\right) \\
E_{r r} & =E_{r r}^{r e f} \cdot\left(\frac{V_{c c}}{V_{R}^{r e f}}\right)^{K_{v 2}} \cdot\left(1+K_{T, r r} \cdot\left(T_{j}-T_{j}^{r e f}\right)\right)
\end{aligned}
$$

Reference losses $E_{o n+o f f}^{r e f}$ and $E_{r r}^{r e f}$ are given in datasheets as the polynomial function in (17). The average switching losses, using (15) and as a function of phase-current $I_{c}$ and switching 
frequency $f_{s w}$, as well as the sum of the energy loss of all the switching transients given with (18), are calculated with (19) [31], [32].

$$
\begin{gathered}
\mathrm{E}_{\mathrm{sw}}=\mathrm{E}_{\text {on }}+\mathrm{E}_{\text {off }}=\left(\mathrm{a}+\mathrm{b} \cdot \mathrm{I}_{\mathrm{C}}+\mathrm{c} \cdot \mathrm{I}_{\mathrm{C}}^{2}\right) \\
E_{s w, a v g}=\frac{1}{T_{0}} \sum_{n} E_{s w}(i)=\left(\frac{a}{2}+\frac{b \cdot \hat{\mathrm{I}}_{\mathrm{c}}}{\pi}+\frac{c \cdot \hat{\mathrm{I}}_{c}^{2}}{4}\right) \\
P_{s w, a v g}=f_{s w} \cdot E_{s w, a v g} \cdot \frac{\mathrm{V}_{\mathrm{DC}}}{\mathrm{V}_{\text {ref }}} \cdot\left(1+\mathrm{K}_{\mathrm{T}_{\mathrm{j}}} \cdot\left(T_{j}-\mathrm{T}_{\mathrm{ref}}\right)\right)
\end{gathered}
$$

Similar equations to (14) and (19) are derived for the antiparallel diode, with the difference being the adjustment in current direction and consequently the phase delay of the conduction and the power factor angle. A more extended explanation and derivation of these equations can be found in [31]-[33]. Furthermore, when the VSC of the same topology is operating in rectifier mode (in case of the MSC), the current and pulse pattern in (12) and (13) need to be adapted in relation to how the converter is being controlled.

\section{Lifetime Estimation}

For lifetime estimation, the cycles in the junction temperature change observed for each chip (diode and IGBT) of a module, are counted. This counting is done by implementing a rainflow algorithm where cycles and half cycles between temperature reversals are counted according to the ASTM E1049 standard [34]. Then, the quantified lifetime evaluation is done using datasheet $\mathrm{B}_{10}$ curves and post-processing of the matrices produced by the rain-flow algorithm. In this paper, the evaluation and processing of the exported matrices has been undertaken using the data analysis package Pandas in Python [35].

For evaluating lifetime, two parameters from the counted cycles are considered: the range (amplitude) of the temperature swing $\Delta T$, and the mean value of the temperature swing $T_{m}$. From the resulting cycles in the rain-flow matrix, cycles smaller than $5{ }^{\circ} \mathrm{C}$ are discarded because their effect in the consumed lifetime is negligible compared to larger cycles, and additionally this lifetime evaluation method is less suited for evaluating the effect of very small cycles accurately [18], [36]. The remaining cycles in the rain-flow matrix, are evaluated against $\mathrm{B}_{10}$ lifetime curves [37], and a cumulative lifetime consumption (damage) is calculated for the total effect of all cycles. From the perspective of the wear-out, the bond-wire connections of the diode and the IGBT chips are identical and are referenced to the same $B_{10}$ curves [37].

$$
N_{f}=a \cdot(\Delta T)^{-n} \cdot e^{E_{a} /\left(k \cdot T_{m}\right)}
$$

The calculated lifetime that is used in this paper is based on the equation shown in (20), where $N_{f}$ is the number of cycles to failure; $a, n$ and $k$ are constants; and $E_{a}$ is the activation energy [7]. The equation is not applied directly, but by using the information in $\mathrm{B}_{10}$ curves. The curves themselves are a result of applying a variation of this equation for a fleet of tested devices by manufacturers, where the parameters of the equation have been defined by statistical analysis of the failures for the tested devices [37]. Curve fitting $B_{10}$ curves to get the parameters for the equation can yield high inaccuracy for some values given that the number of data points is not high enough in order to have a satisfactory 'goodness of fit'. Thus, applying $\mathrm{B}_{10}$ data as look-up tables is a solution to use the accessible information without additional inaccuracy.

Interpreting the data in lifetime curves can also introduce inaccuracy: the number (y-axis) is in a logarithmic scale, while for this type of technology and the failure mode considered here, the lifetime data is summarized by 13 curves (for different $T_{m}$ ) each defined by 9 data points (different $\Delta T$ ). For each curve, extrapolation needs to be done, and the introduced accuracy of the extrapolation needs to be minimal. For this, at every $\mathrm{B}_{10}$ defined data point (for different $\Delta T$ in $\mathrm{x}$-axis), the y value, i.e. $N_{f}$ from (20), has been used as given from manufacturers. Outside of the defined points (e.g. for cycle range of $25{ }^{\circ} \mathrm{C}$ which falls between the defined $20^{\circ} \mathrm{C}$ and $30^{\circ} \mathrm{C}$ ), a logarithmic extrapolation has been used.

The total damage effect is given by (21) where the lifetime evaluation of cycles is calculated as the ratio of $n_{i}-$ the number of counted cycles at a certain temperature swing and average temperature, and $N_{f, i}$ - the number of cycles that the module is expected to withstand until failure for the same thermal cycling conditions.

$$
D_{B 10}=\sum_{i} \frac{n_{i}}{N_{f, i}}
$$

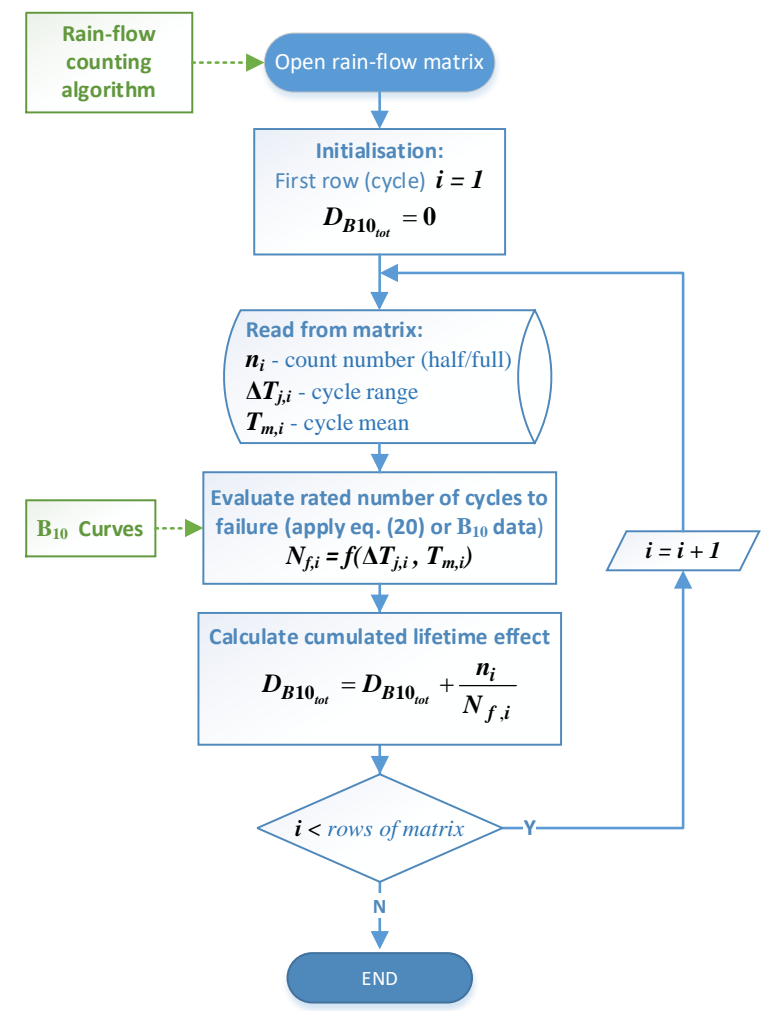

Fig. 2. Diagram of function for lifetime estimation procedure

The lifetime evaluation procedure is applied as a recursive function, shown in the diagram in Fig. 2. First, rain-flow matrices with rows that contain every counted cycle are opened. Each row contains information about the counted cycle, including the 
range $\Delta T$ and average value $T_{m}$ of the junction temperature cycle. Using these values, as well as the number of counted cycles $n_{i}$ (full and half cycles), eq (20), and Miners rule in (21) are applied while looping through all rows of the matrix, and resulting lifetime effect is calculated.

\section{CONTROL ASPECTS OF THE WIND TURBINE AND THE} CONVERTERS

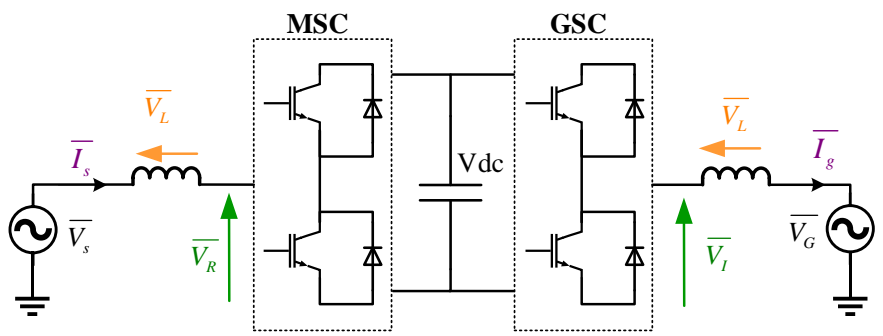

Fig. 3. Layout of the connection between the PMSG and WF AC grid per phase

The layout of the connection between the PMSG WT generator and the WF array AC network is shown in Fig. 3. The assumed current directions and voltage polarities are labelled and have been used for designing the control of the MSC and GSC. The analysis for the rest of the paper is focused on one IGBT and diode (one phase-module) - as far as the lifetime consumption is considered, the analysis will be identical if applied for the other modules in the other converter phases and legs of the MSC and GSC.

The control of the WT and converter for the model in this paper includes several layers of control that have been observed to be relevant for the considered transients, starting from the inner current loop of the converters, the outer power/torque control, as well as the WT blade pitch control for limiting the generated power above rated speed. The control parameters for these different layers are given in Table 1. The control design and the differences in control between the MSC and GSC are discussed in the next subsections.

Table 1. Control parameters for the converter current and power loops as well as collective blade pitch control ${ }^{1,2}$

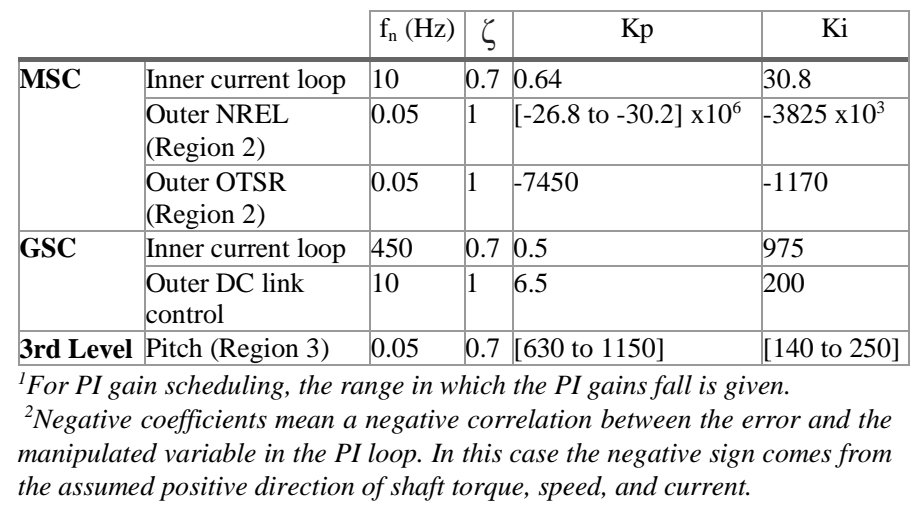

\section{A. Grid-Side Converter (GSC)}

The grid-side converter is controlled using voltage-oriented control in dq vector coordinates [38]. The phasor diagram is shown in Fig. 4. Apart from the control design, this phasor is used for calculation of the losses for the GSC, where the right phase angles in the current waveform and the duty ratio of the chips need to be used when evaluating the chip losses as explained in Section II. B. The outer control loops for the GSC are the real and reactive power loops, given in (22) and (23). The active power loop is designed and tuned to respond to the power output from the WT so that the DC link voltage remains constant and all the generated power from wind is injected to the grid. The reactive power loop can be used to provide grid voltage support independent of the real power output, and this change in power factor is an additional dynamic that will affect the thermal cycling and the reliability of the GSC [39], [40]. Phase-Locked Loop (PLL) dynamics are not considered in the converter control because the WT is assumed to be connected to a large modern offshore system, where the frequency will be set by the offshore MMC VSC HVDC converter which is assumed to offer a stiff AC source as a 'grid forming' reference. Therefore apart from the short synchronizing instant when the WT connects to the system, the effect of the PLL in this system will be minor. The effect of the PLL dynamics would be more significant, and reflected in the converter operation, in a case when the methodology is adapted for a WT that is connected to a weak grid.

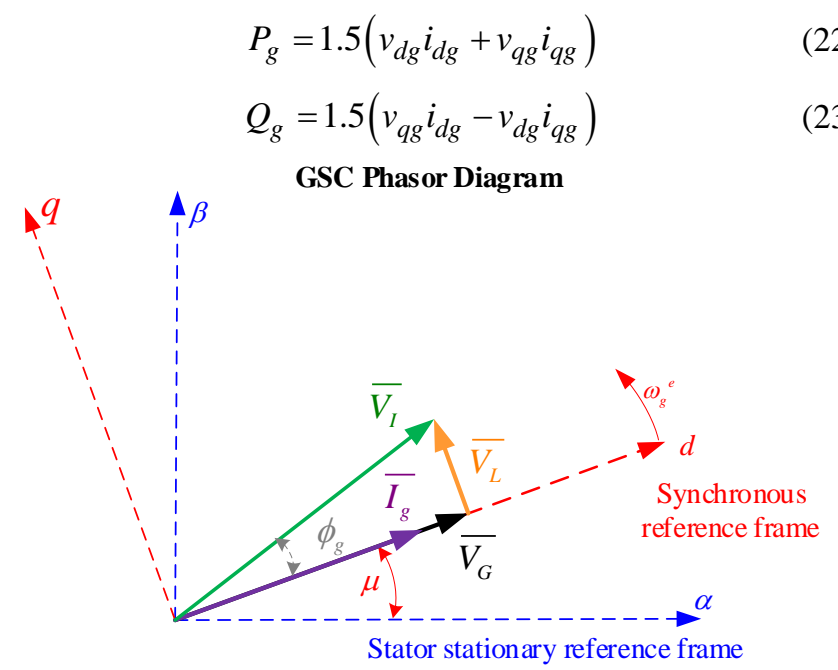

Fig. 4. Grid Side Converter phasor diagram for zero d-axis control and unity power factor connection with the grid.

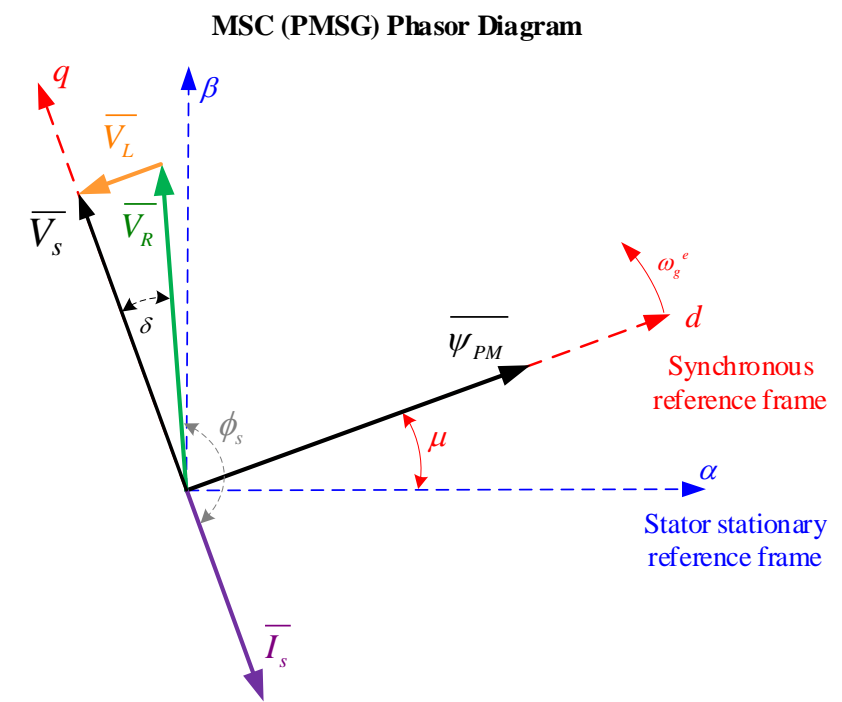

Fig. 5. Machine Side Converter phasor diagram for Field-oriented control and rectifier operation of the VSC. 
In Fig. 4 and Fig. 5 the voltage and current phasors are consistent with the annotations in Fig. $3 ; \phi_{g}$ and $\phi_{s}$ are the phase angles between the current and the voltage in the GSC and MSC terminals respectively; $\omega_{g}{ }^{e}$ is the electrical frequency of dq synchronous reference frame; $\mu$ is the phase difference between dq (synch.) reference frame and $\alpha \beta$ (stator) reference frame; $\delta$ is the phase angle between machine generated voltage and the MSC AC terminal voltage ( $V_{s}$ and $V_{R}$ in Fig. 3.).

\section{B. Machine-Side Converter (MSC)}

The machine-side converter is controlled in vector coordinates with field-oriented control of the PMSG [38]. The phasor diagram is shown in Fig. 5. The phasor diagram represents operation of the inverter VSC topology in rectifier mode - the current is lagging the voltage by $\phi_{s}=\angle(\pi-\delta)$. The outer loop of the MSC is usually designed to optimize WT operation and power generation. For the outer loops of the MSC, three different design options for the power curve tracking mechanism of the WT are discussed in the following section.

\section{WT Control: Maximum Power Point Tracking (MPPT) and Pitch Control}

The WT generator is controlled for Maximum Power Point Tracking (MPPT) at the second region of the power curve (above cut-in and below rated wind speed). This control adjusts the torque and speed of the WT in order to generate the optimal power as the wind speed fluctuates. The aim is not just to track the power curve, because other factors such as mechanical loading torque need to be taken into account. In addition, the choices in this control affect the reliability and thermal loading of the power converter as the rest of this paper examines.

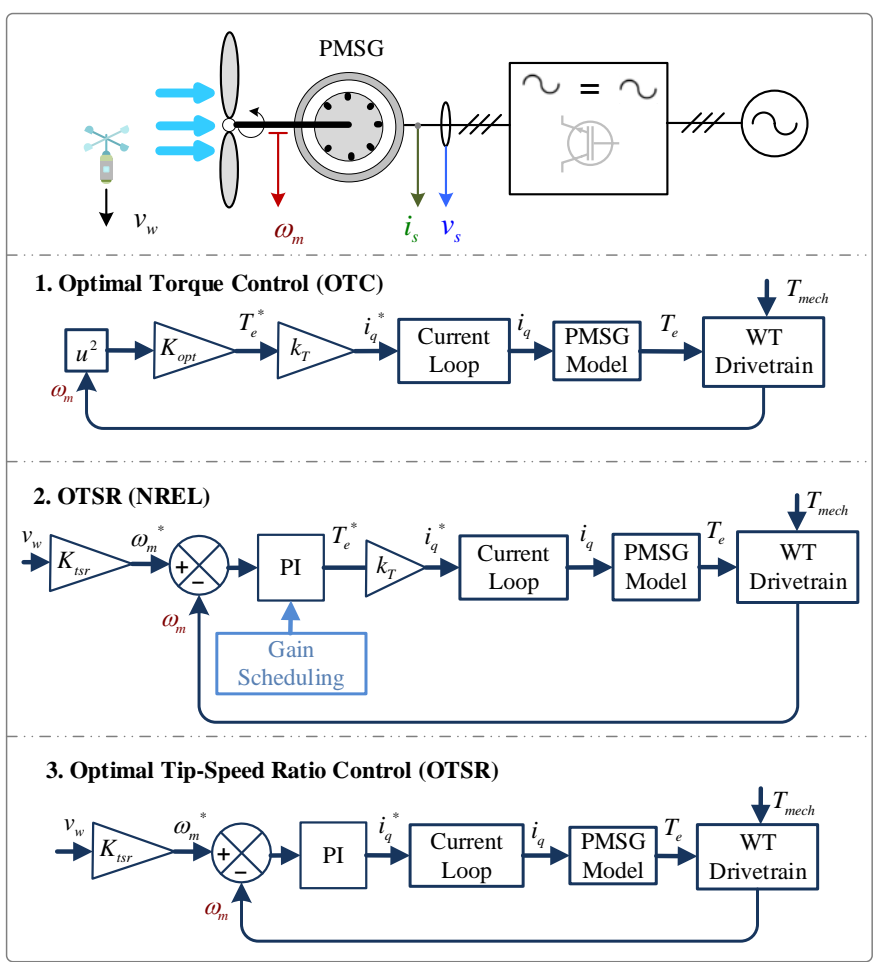

Fig. 6. Control loops for the three MPPT implementations compared in this paper: 1. Optimal Torque Control (NREL); 2. OTSR (NREL) - using FAST with gain scheduling; and 3. Optimal Tip-Speed Ratio (OTSR) Control - using swing equation and textbook control design methods.
The MPPT control in this paper is realized in three different ways: two controls suggested by NREL for their definition WT, and the third is a simpler classic speed control loop designed for the adapted configuration of the $5 \mathrm{MW}$ WT in this paper. The generic MPPT controller that was originally implemented for the NREL 5MW baseline turbine is Optimal Torque Control (OTC) which is shown as the first option in Fig. 6 [22]. This OTC ensures MPPT by having a defined torque set-point for any generator speed, using relation given by (24); where coefficient $K_{o p t}$ is calculated for power-maximizing (optimal) values of power coefficient $C_{p}$ and tip-speed ratio $\lambda$ as in (25).

$$
\begin{gathered}
T_{e}=K_{o p t} \cdot \omega_{g}{ }^{2} \\
K_{o p t}=\frac{\pi \rho R^{5} C_{p}}{2 \lambda^{3}}
\end{gathered}
$$

The OTC does not give much flexibility in controlling the response characteristics and in practice can have a significant steady-state error because of the inaccuracy in the calculation of $K_{\text {opt }}$ [41]. In order to match with industry standards that employ a more advanced MPPT, an updated controller was suggested by NREL in [41] for the same WT. This control has been developed by advanced techniques and using FAST software. The MPPT is done by keeping an Optimal Tip-Speed Ratio (OTSR) with an outer PI loop which employs gain scheduling and is tuned to regulate the PMSG torque based on the measured rotor speed. This is shown as the second option in Fig. 6. The third option for MPPT in Fig. 6 is an OTSR loop designed by the authors here using a differential equation based on the swing equation. Essentially this is a simpler version of OTSR than the one provided by NREL (option 2 in Fig. 6), with no gain scheduling or any complex control design or FAST software. As demonstrated by the results in the next sections, if tuned correctly and for the particular WT configuration here, this simpler control design provides a WT response that is very close to the advanced OTSR version by NREL. The used tuning parameters for the two OTSR options are given in Table 1.

The dynamics of the response of the pitch angle control and the dynamics above rated speed are also relevant for the thermal loading of the converter. The blade pitch control has been considered with a collective pitch angle for all three WT blades and the control loop has been designed with a PI controller using gain-scheduling adapted from the original reference [22].

\section{STEADY-STATE ANALYSIS}

\section{A. WT Step Response}

The response of the WT during a step change of the wind input from 9 to $10 \mathrm{~m} / \mathrm{s}$ for all three different controls is shown in Fig. 7 and Fig 8. Both of the OTSR methods have a quicker response than the OTC, and have some degree of overshoot. This faster response comes at the cost of having a larger generator torque (Fig. 8) applied to the shaft for providing the necessary acceleration. For the OTC, the torque changes depending on the measured rotor speed and cannot be controlled for changing its acceleration or deceleration rate. Note that the transient response i.e. torque effort in this paper (Fig. 8) for both OTSR (NREL) and OTSR options is larger than in the WT in reference [41] because of the drivetrain alterations made in this paper 
when adapting the WT for a gear-less application. This meant elimination of the multi-stage gearbox (with ratio of 97:1), which resulted in having a considerably larger torque on the generator shaft. The elimination of the gearbox makes the transient response highly dependent on the large turbine inertia which also diminishes the potential for improved control with gain scheduling - this also results in the very small difference in response between the advanced control of the NREL OTSR and the simplified OTSR. The large inertia and the slow response for the OTC case, contributes to a behavior that filters out some fast wind speed turbulences without reflecting them to the torque response - this means less mechanical drive-train and power electronics stress, but also means lower effectiveness of power curve tracking. The other two controls give an opportunity to control this response, but there can be a compromise in reliability and converter fatigue as demonstrated by the analysis in the rest of this paper.

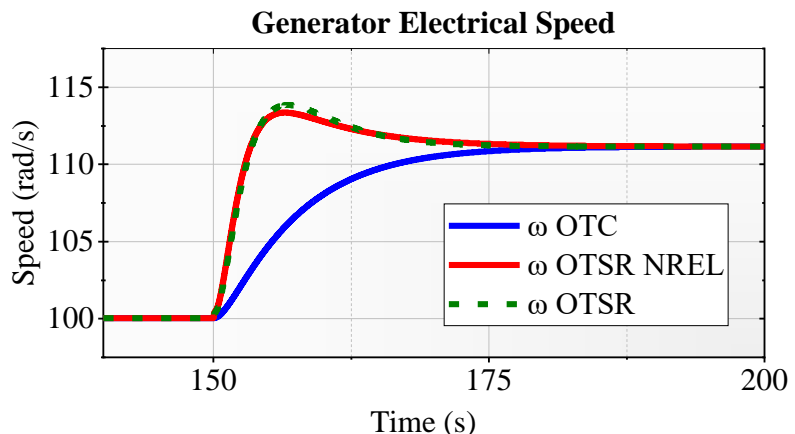

Fig. 7. Generator speed step response for wind speed change of 9 to $10 \mathrm{~m} / \mathrm{s}$ for the three different MPPT control implementations

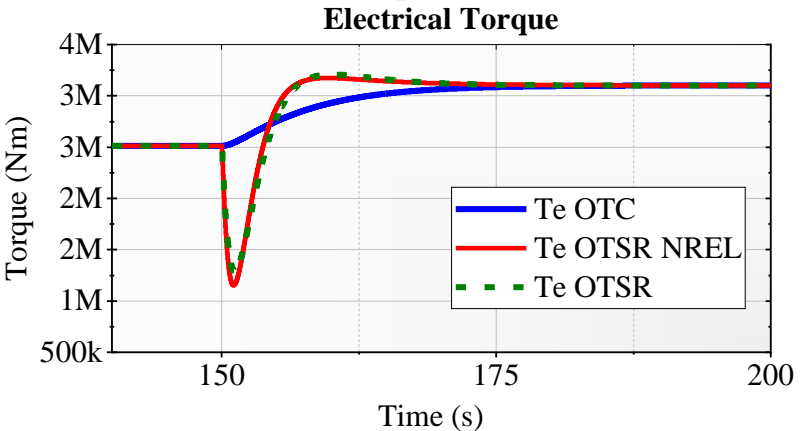

Fig. 8. Generator speed step response for wind speed change of 9 to $10 \mathrm{~m} / \mathrm{s}$ for the three different MPPT control implementations

\section{B. Steady-State Converter Thermal Loading}

The thermal behavior of materials can be described by equivalent circuits that contain thermal resistances $\mathrm{R}_{\mathrm{th}}$ and capacitances $\mathrm{C}_{\mathrm{th}}$, which can be analyzed like electrical circuits. Generally, two types of networks are built for making this analogy, Foster and Cauer networks. In a Foster network, RC elements represent mathematical transfer functions and time constants; while for Cauer networks, RC elements indicate a "ladder" type connection that more correctly represent the physical properties of material heat conductivity for $\mathrm{R}_{\mathrm{th}}$ and heat storage capacity for $\mathrm{C}_{\mathrm{th}}[11]$. For the purpose of power electronic module thermal analysis, the transformation to a Cauer network enables connecting interfacing materials (e.g. thermal grease and heatsink) in series to build a full thermal network that can model more realistically the heat flow and the temperature [42], [43].

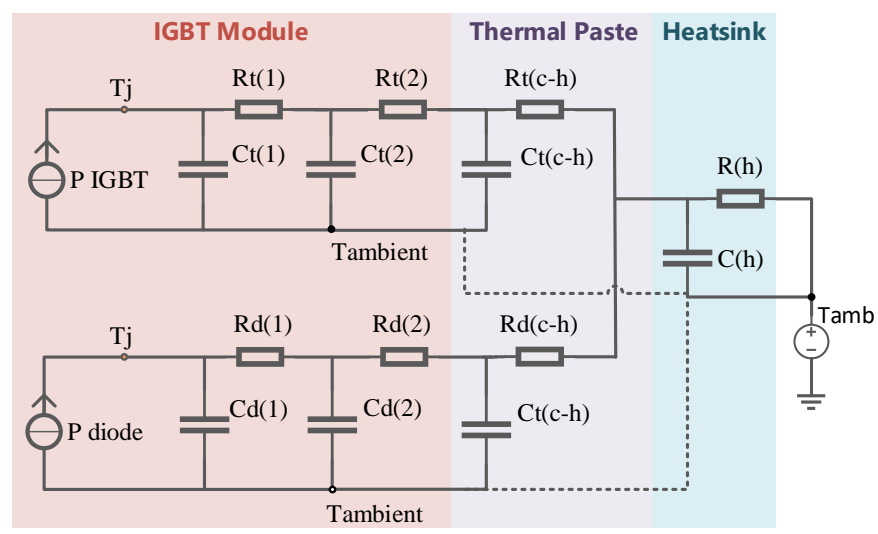

Fig. 9. Cauer thermal network of one IGBT module connected to a heatsink

Table 2. Power module thermal parameters

\begin{tabular}{|c|c|c|c|c|}
\hline & \multicolumn{2}{|c|}{ Foster [26] } & \multicolumn{2}{|c|}{ Cauer (transformed) } \\
\hline & IGBT & Diode & IGBT & Diode \\
\hline Thermal & $\mathrm{r} 1=12.75$ & $\mathrm{r} 1=25.5$ & $\operatorname{Rt}(1)=4$ & $\operatorname{Rd}(1)=8.47$ \\
\hline Thermal Time & $\tau 1=151$ & $\tau 1=144$ & $\tau 1=6.76$ & $\tau 1=6.74$ \\
\hline Constant [ms] & $\tau 2=5.84$ & $\tau 2=5.83$ & $\tau 2=130.45$ & $\tau 2=124.5$ \\
\hline
\end{tabular}

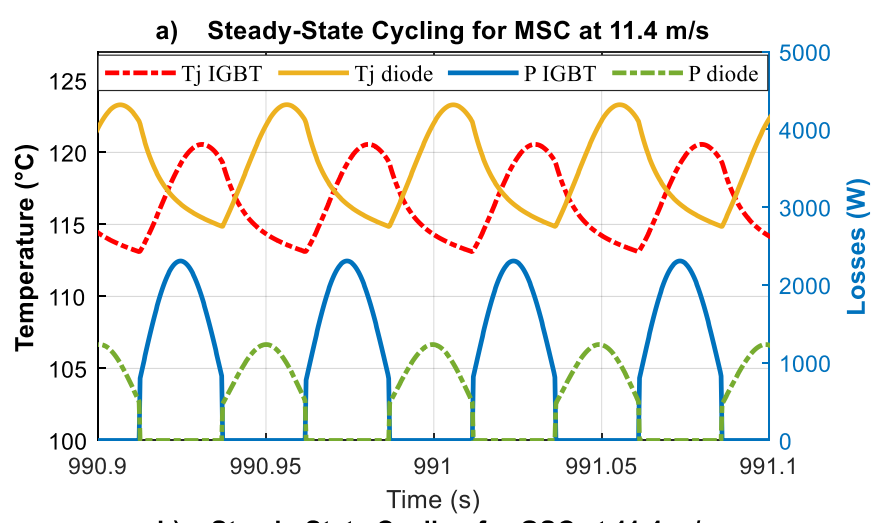

b) Steady-State Cycling for GSC at $11.4 \mathrm{~m} / \mathrm{s}$

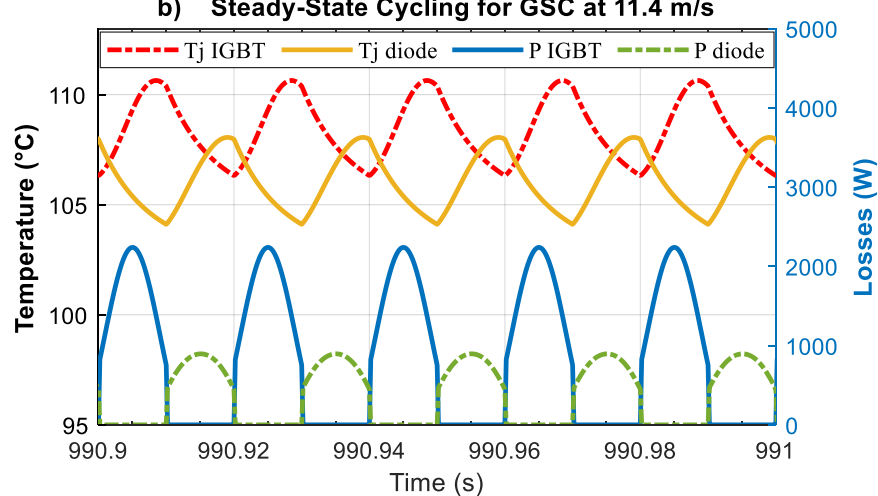

Fig. 10. Thermal cycling and power losses for the IGBT and diode for WT steady-state operation with rated wind input of $11.4 \mathrm{~m} / \mathrm{s}$ : a) MSC, and b) GSC

The Cauer thermal network used to represent the power module connected to the heatsink is shown in Fig. 9. The power module's Foster thermal parameters were taken from the datasheet and transformed to Cauer parameters using the Laplace-domain method from [42] and are shown in Table 2. Thermal grease resistance of $0.012 \mathrm{~K} / \mathrm{W}$ and $0.024 \mathrm{~K} / \mathrm{W}$ per chip is added in series for case-heatsink connection of the IGBT and the diode respectively [26]. The used values for the resistance and thermal time constant of the heatsink are $0.05 \mathrm{~K} / \mathrm{W}$ and $100 \mathrm{~s}$ which are consistent with commercial heatsink solutions for similar converter devices [44]. This completes the simplified representation of the thermal network from junction to 
ambient (converter cabinet) - more complex converter thermal network representations that include effects such as cross coupling can be considered [33], [43]. The ambient (i.e. converter cabinet) temperature is set to remain constant at $25{ }^{\circ} \mathrm{C}$ for the purpose of analyzing only converter thermal profile variations resulting from the WT operation. The steady-state results of the loss and thermal models have been verified by comparison to results from manufacturer's simulation tool [45].

The thermal cycling in steady-state operation for rated input speed $(11.4 \mathrm{~m} / \mathrm{s})$ as well as the losses in each of the module chips are plotted in Fig. 10 a) and b) for the MSC and GSC respectively. The average losses for both MSC and GSC as well as the average junction temperatures for this same steady-state operation at rated wind are shown in Fig. 11. In Fig. 10 it can be noticed that there are differences in magnitude (range $-\Delta T)$ and absolute temperature (mean $-T_{m}$ ) of the cycling between the MSC and GSC. The difference in cycling range between the converters comes from their different $\mathrm{AC}$ waveform frequency, which governs the transfer of current between the diode and IGBT switches and consequently the steady-state thermal cycling. The frequency of the GSC current is $50 \mathrm{~Hz}$, while on the MSC it varies with the wind speed and for this particular generator design is maximally $20 \mathrm{~Hz}$ at rated speed and in the pitch control region. This difference in frequency can be seen in the frequency of the temperature cycling in Fig. 10 and makes the temperature swings in the MSC roughly twice as large as the ones in the GSC. The other difference between the MSC and GSC is that because of the difference in operation (rectifier vs inverter Fig. 4 and Fig. 5), for the MSC side the diode losses are about $25 \%$ higher than those in the GSC as seen in Fig. 11. a). This is enough to make the diode average temperature surpass that of the IGBT in the MSC, even though the total losses in the IGBT are still larger (mainly because of the switching losses). This higher chip temperature for lower losses is a consequence of the diode being a smaller chip and having a larger thermal resistance than the IGBT (see Table 2). Therefore, as a consequence of the variable and lower frequency on the machine side compared to the grid side, as well as of the difference in operation mode, the MSC is more thermally stressed than the GSC in steady-state operation both in terms of temperature swing and mean temperature.

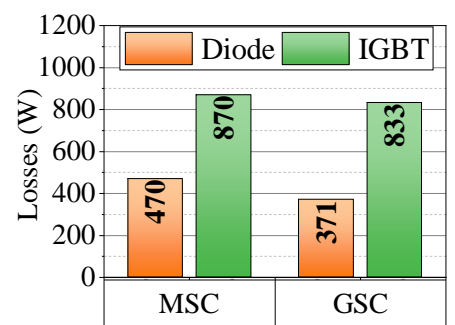

a) Average Losses

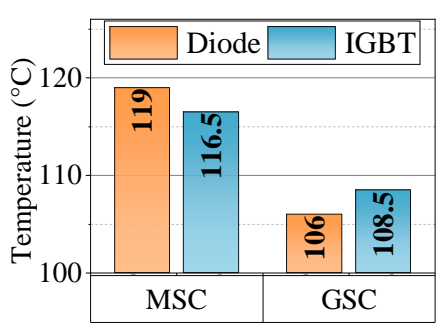

b) Junction Temperature
Fig. 11. a) Average chip losses and b) Average chip junction temperature, for the MSC and the GSC for steady-state WT operation at rated wind of $11.4 \mathrm{~m} / \mathrm{s}$.

\section{LIFETIME ESTIMATION FOR TURBULENT Wind PROFILE OPERATION}

The thermal cycling which is a consequence of transients in the WT operation is by a large factor greater and more significant than the steady-state fundamental frequency cycling. This

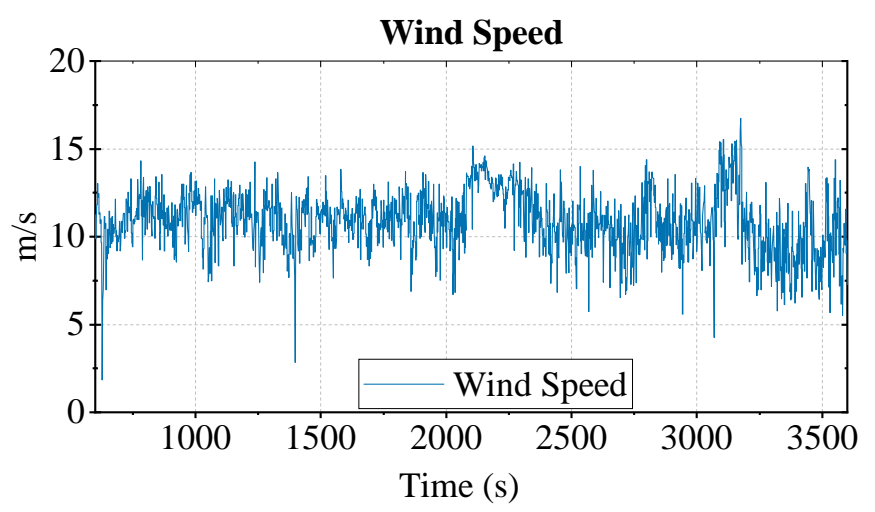

Fig. 12. Turbulent wind profile in an offshore site in the UK (November 2018).

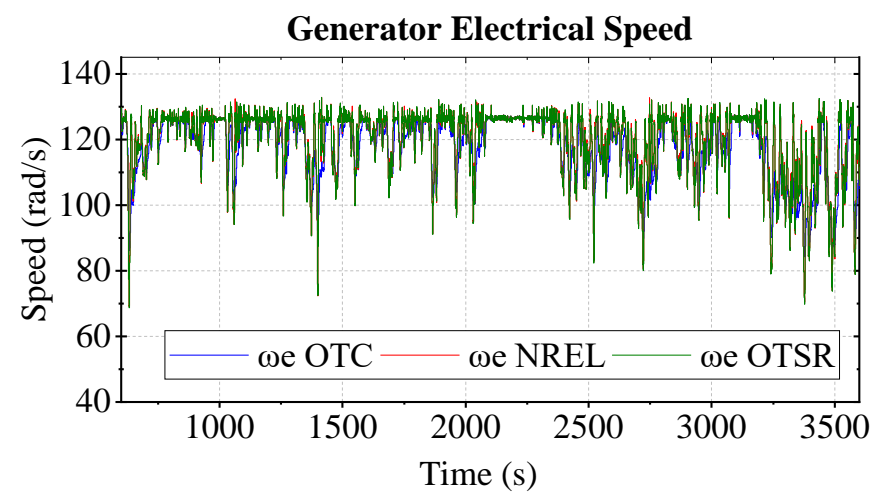

Fig. 13. Generator speed change for the turbulent wind profile.
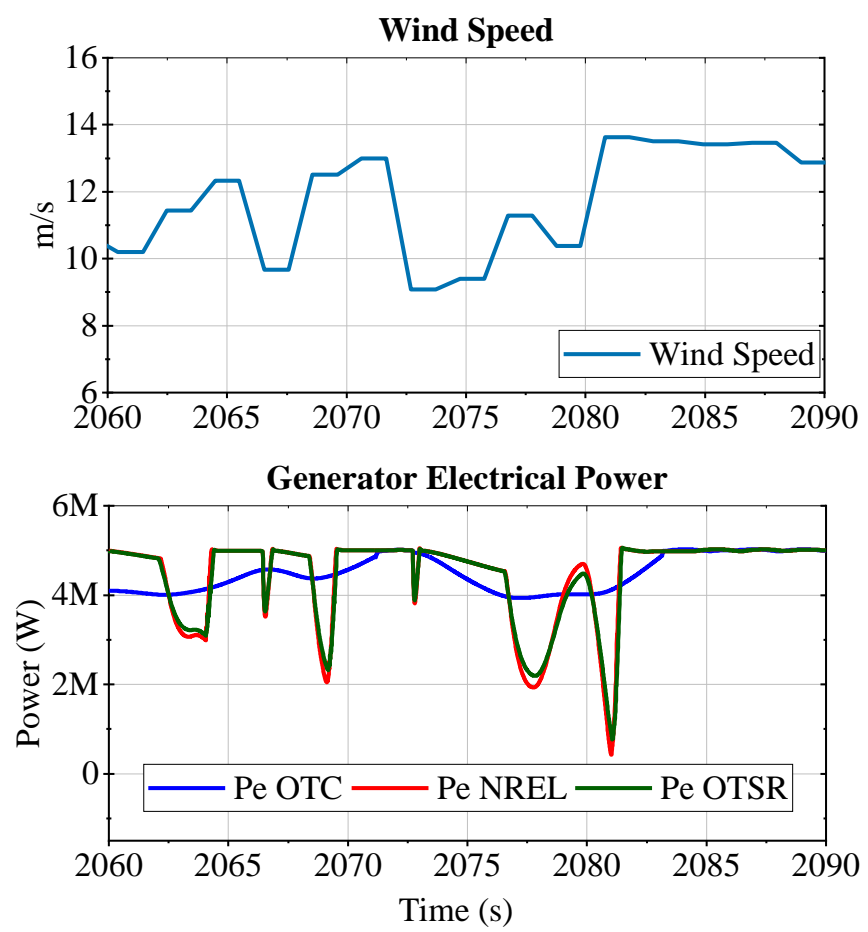

Fig. 14. Wind turbine response for the turbulent wind profile (zoomed in to show 30 s for clarity)

cycling is studied in this section and a comparison is made between the control strategies of the WT. The WT and converter thermal loading model has been run with a wind profile shown in Fig. 12. This wind profile is from measurements with 1 second resolution in November 2018 at a real offshore wind turbine in the UK. The simulation has been run for 50 minutes and the resulting generator speed change is shown in Fig. 13 for the 


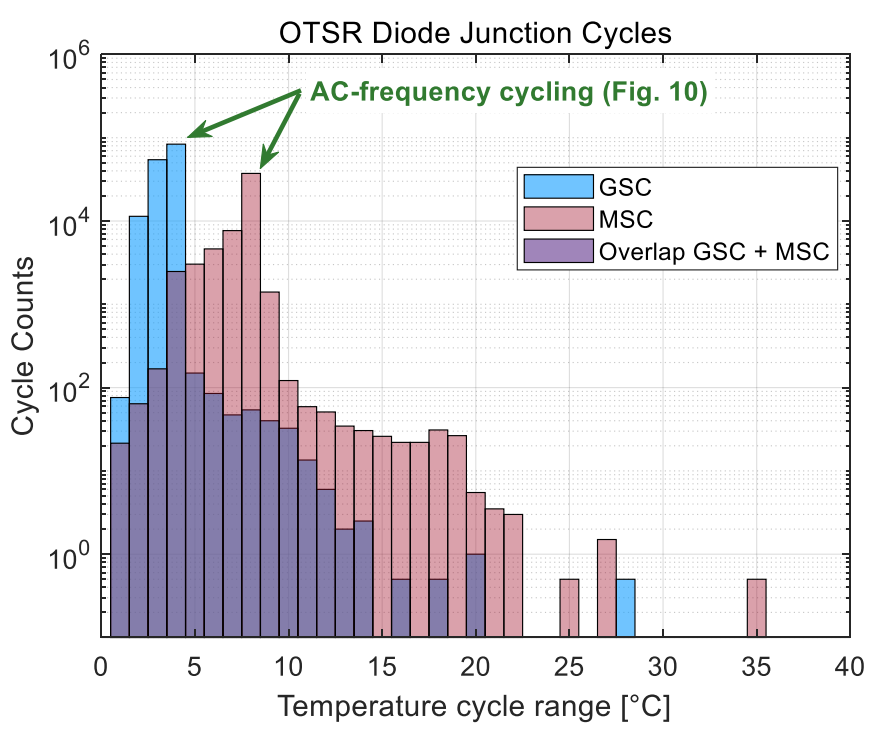

Fig. 15. OTSR, diode cycle count histogram GSC vs MSC (range)

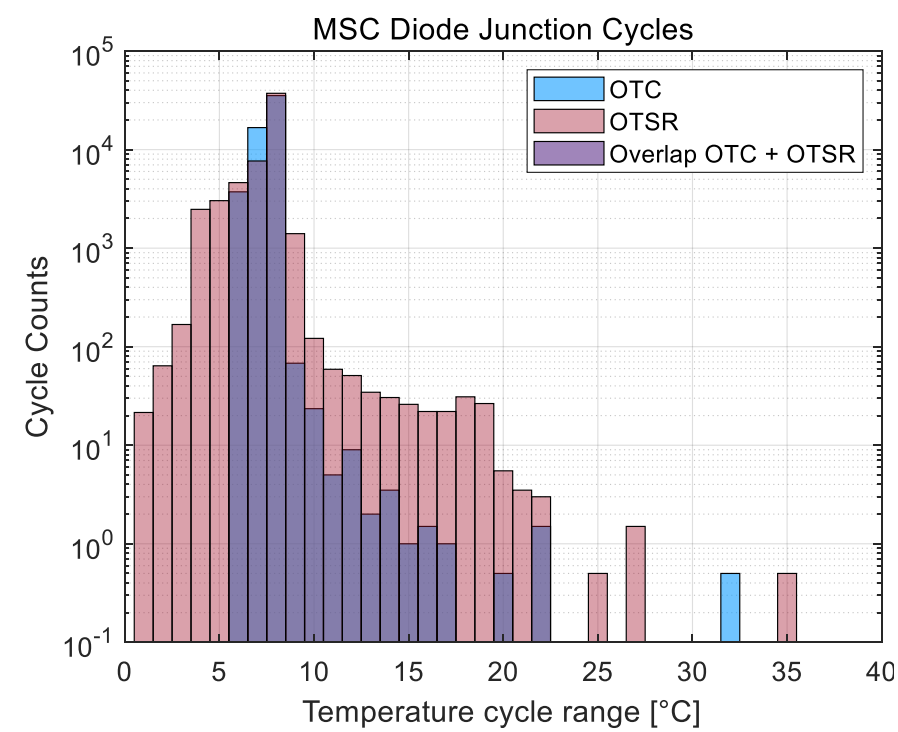

Fig. 17. MSC, diode cycle count histogram OTC vs OTSR (range)

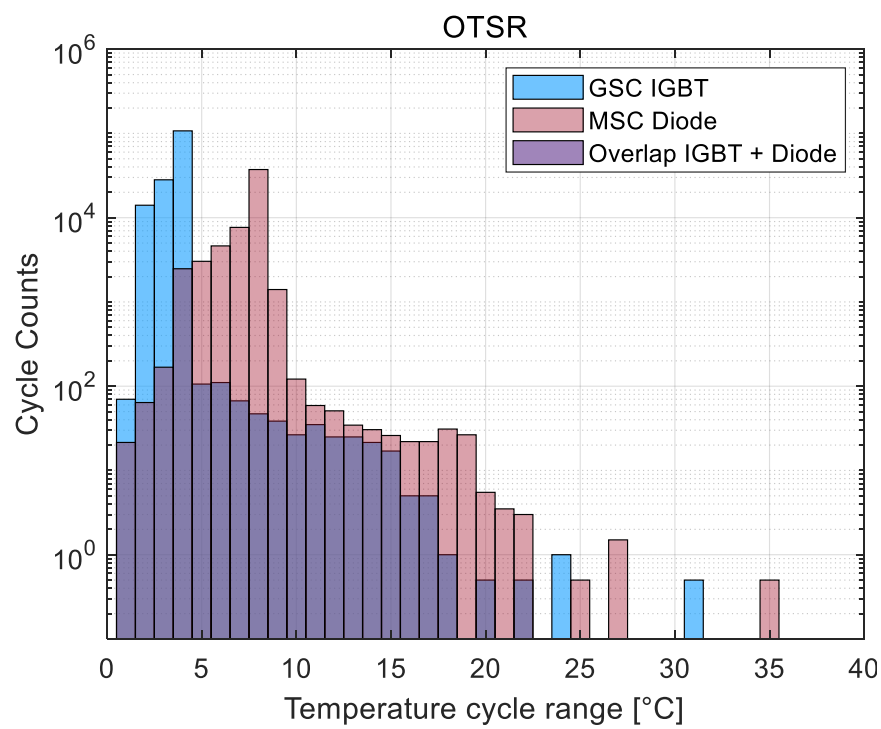

Fig. 19 OTSR, cycle count histogram of most thermally stressed chips, GSC IGBT vs MSC Diode (range)

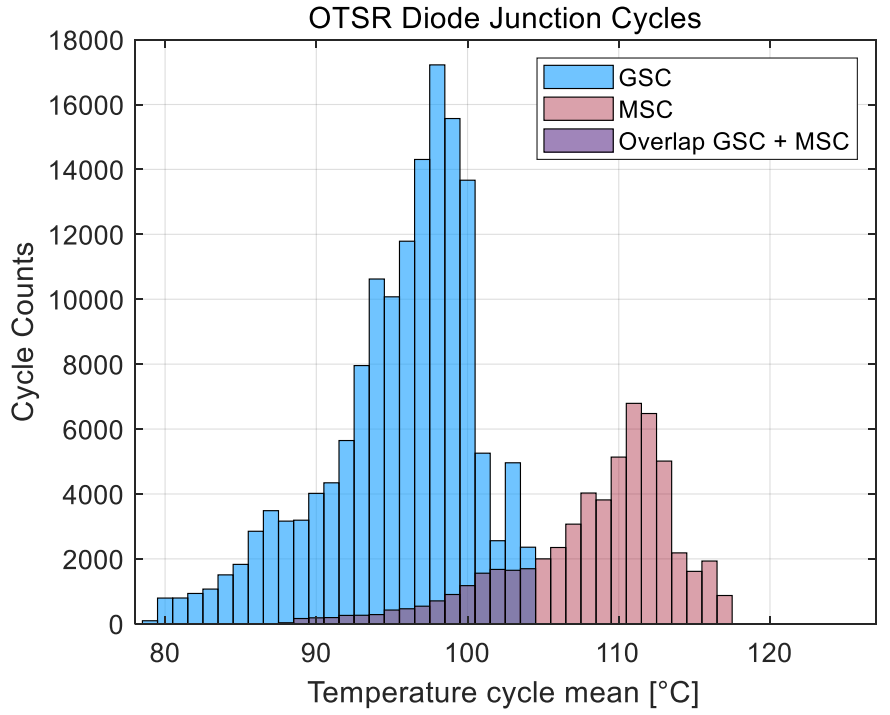

Fig. 16. OTSR, diode cycle count histogram GSC vs MSC (mean)

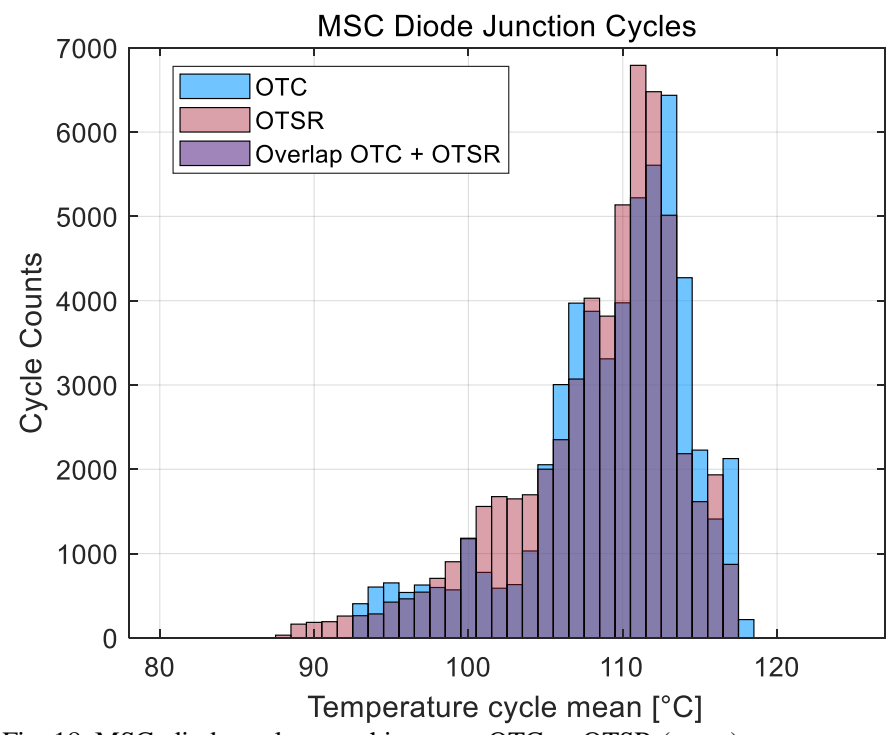

Fig. 18. MSC, diode cycle range histogram OTC vs OTSR (mean)

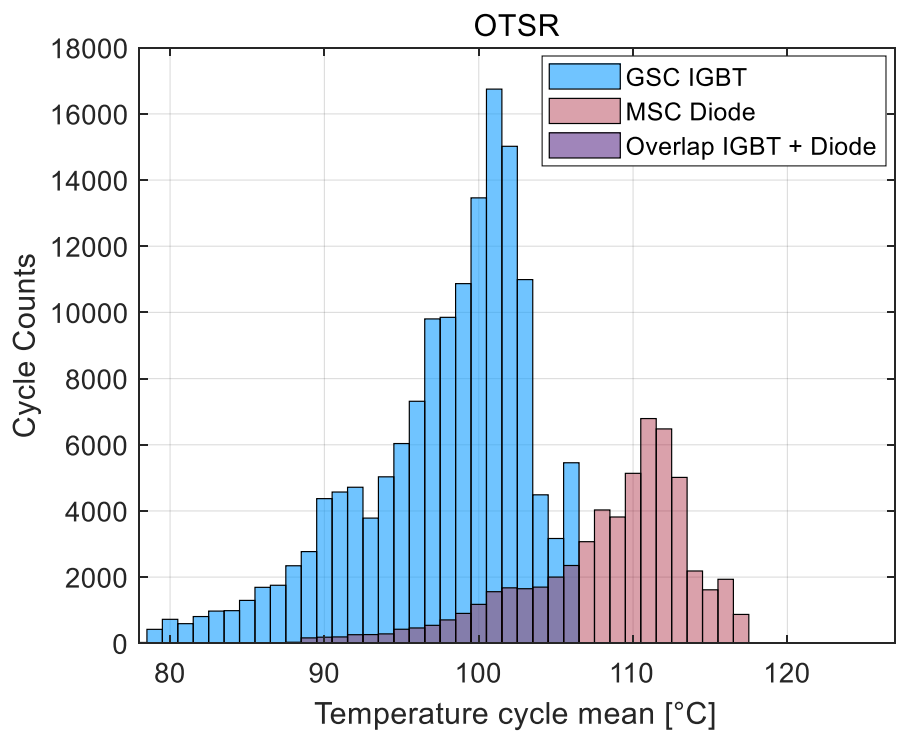

Fig. 20 OTSR, cycle count histogram of most thermally stressed chips, GSC IGBT vs MSC Diode (mean) 
three different MPPT controls. To show the differences between the three considered controls (from Fig. 6), the results for generator generated electrical power are given in Fig. 14 in a timespan of 30s (from the full analyzed 50 minutes) for better clarity.

\section{A. Assessment of Temperature Cycles}

The histograms of the GSC vs MSC comparison of counted cycles for the diode chip with OTSR operation are shown in Fig. 15 and Fig. 16. In the histogram in Fig. 15, the AC frequency cycles, which represent the highest number of counted cycles, have been annotated. These cycles result from current conduction through the IGBT and parallel diode at the different half periods of the AC cycle - the same cycling that was observed in steady-state operation (Fig. 10). The rest of the cycles - more importantly for the reliability, the larger swings on the right of the histogram - are the ones that are simulated by considering the mission profile and by using the high resolution turbulent wind profile and the WT operation. As in the case of the steady-state analysis, it can be seen that both in terms of cycle ranges and cycle means, the MSC is the converter with the higher thermal stress and that has the higher probability of failure due to this failure mechanism. It should be noted how substantial the thermal stress cycles that result from the detailed mission profile consideration are.

The comparison of the counted cycles in the MSC diode for two control methods is shown in Fig. 17 and Fig. 18. From the histograms it is clear that the OTSR counted cycles have a considerably larger cycle range than the OTC (Fig. 17), while the cycle mean is more similar - although there is still a difference in the number of cycles in the separate bins (Fig. 18). It is important to note that in the simulation the controls differ only in the transient behavior, and in steady-state they reach the same value (Fig. 7 and Fig. 8) - therefore any difference in counted cycles and lifetime is because of the modelling of transients. The number of AC frequency counted cycles is essentially equal for both controls (Fig. 17) - this number is equal because the current waveform frequency is much larger than the frequency of the generator control, and is hardly affected by the transients of the generator. However, a larger difference can be seen in the other cycles that are much lower in number and result from the control interaction with the wind profile. It can be seen that the slow response of the OTC filters out, and does not track, the faster turbulences in the wind speed (see Fig. 14), which results there being no cycles with a range lower than $5{ }^{\circ} \mathrm{C}$. The OTSR responds much faster and these cycles are present. Additionally there is a significant difference in the large cycles. Note that because of the logarithmic dependence of lifetime on temperature range, although the AC-frequency cycles dominate the total number of counted cycles, this dominance does not necessarily translate to a dominance in the resulting lifetime consumption. Therefore, the final step of quantifying the lifetime is a major part of the analysis.

From the analysis in steady state, the most thermally stressed chip in the MSC is the diode while in the GSC the IGBT. For the turbulent operation, the comparison of thermal cycles between these most thermally stressed switches in the different converters for OTSR control is shown in Fig. 19 and Fig. 20. Similar histograms that show the thermal loading can be produced for the other combinations of controls and devices; or for less ambiguous assessment the comparison can be made using the lifetime consumption evaluation.

\section{B. Assessment of Consumed Lifetime}

The observations that are made while analyzing the histograms of cycle counts are consistent with the observations when the layer of evaluating the lifetime estimation is added to the analysis. The quantified lifetime consumptions of all three control scenarios in the 50-min analyzed period are shown in Fig. 21. These lifetimes have been calculated applying the methodology explained in Section II. C. and Fig. 2. It can be seen that the most affected bond-wire connection is the one connecting the diode on the MSC for the scenario of NREL OTSR control. This quantifies the qualitative observations that were made in the histogram analysis: for instance, the consumed lifetime for the MSC side is an order of magnitude higher than for the GSC. Also the lifetime consumption for both of the OTSR controls is around 2 times larger than for OTC - this difference is clear for both chips in the MSC in Fig. 21. In the case of the GSC it is clear only for the IGBT where the difference is more than $50 \%$, while for the GSC diode, the absolute thermal loading is too small for all three controls and a useful relative comparison cannot be made at this scale.

It should be noted that relative lifetime consumption is a proxy for the degree of wear that each of the control schemes induces and their relative impact on converter reliability. It should also be noted that the absolute lifetime consumption on the module by these effects only, is not so large that the failure within 30 years is necessarily inevitable. Nonetheless, for more rigorous calculations of the absolute lifetime consumption, other wear out effects need to be added which can be modelled by other previously established models.
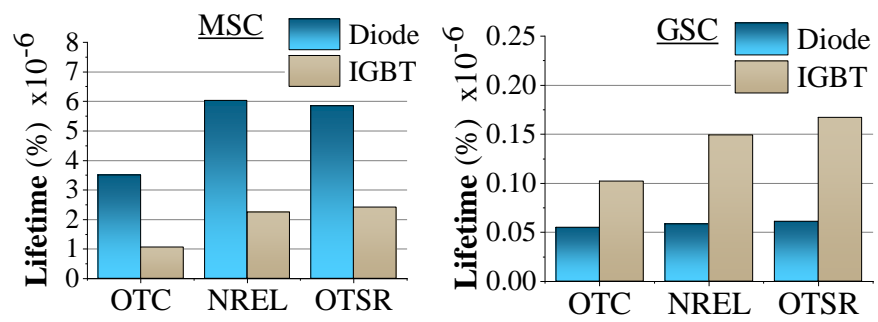

Fig. 21. Comparison of the lifetime consumption of both chips in MSC and GSC and for all three different controls (for operation of 50mins)

The main results of this paper can be further discussed with reference to Fig. 21. First of all these results show the difference in reliability for different chips of a module, for different converters (MSC or GSC), and for differences in-built to the WT generator control strategies. This information can be taken forward to design more reliable systems or mechanisms that will help extend converter lifetime. This model can be combined with a detailed failure detection and localization method such as in [12] where it will be used as an additional parameter to make the localization faster and more accurate.

When comparing the different MPPT strategies it is observed that strategies which track the power curve more closely typically have larger converter lifetime consumption. This can be traced back to the way these control strategies are designed: to have a faster response with an inherent torque overshoot which is consequently also reflected in the machine current and the thermal cycling of the converter. In case this kind of response 
and close tracking of the WT power curve is seen as necessary in a particular application, in this paper we show that additional considerations would be needed to not do this at the cost of considerably lowering the converter reliability. In case of contingencies where it is known that the whole converter is at higher risk of failure (for example there is a malfunction and the cooling system is operating at reduced capacity), the control can be temporarily altered to track the power curve less closely so that complete WT downtime is avoided - until an intervention is undertaken which for offshore WFs can take some time especially during periods with harsh weather conditions.

From the cycle counting results it can be seen that there are counted cycles larger than $20^{\circ} \mathrm{C}$ and up to $35^{\circ} \mathrm{C}$. In the considered 50 minute interval the number of these large cycles is relatively low, but still the lifetime estimation proved them to be highly detrimental for the lifetime. Throughout the operating lifetime of the WT, this number of large cycles will be much larger. In order to predict useful lifetime consumption that is close to what happens in reality, it is important for lifetime models to simulate the effect of these dominating cycles as accurately as possible. To do this, including transients and detailed WT operation is crucial. For the results here, at the worst case scenario (the OTC vs NREL comparison in MSC - Fig. 21), the evaluation of consumed lifetime could be underestimated by more than 50\% if the modelling is simplified and differences in control transients of the WT are neglected.

\section{CONCLUSION}

In this paper a methodology for evaluating the comparative lifetime consumption of an IGBT converter module for a directdrive PMSG WT configuration was presented. The methodology is based on bond-wire lift-off as a dominating failure mode and was demonstrated and applied for steady state and transient operation. Three different control strategies of the WT generator were compared for the WT case study with the particular wind profile input. Using the lifetime consumption methodology, it was evaluated that the control strategies which track the optimal WT power curve more closely have larger converter lifetime consumption. Furthermore, a comparison between MSC and GSC thermal stress and lifetime consumption has been undertaken, identifying where the weakest link of the module is for the different converters and modes of operation. It was identified that the bond-wire that connects the diode chip on the MSC side is the most thermally stressed and with the highest probability of failure.

A discussion was given on how the presented methodology can be useful both in terms of design of the system itself as well as the condition monitoring and maintenance procedures. The results in the paper indicate short operational and control transients in lifetime modelling need to be prioritized and deserve more attention. They can introduce a high number of thermal cycles with large temperature swings and are more problematic than some other aspects which are more commonly considered in lifetime estimation methodologies, such as the long-term seasonal change of wind speed and ambient temperature.

\section{APPENDIX}

Table A.1. Parameters of the WT system configuration

\begin{tabular}{l|cl} 
Parameter & Symbol & Value \\
\hline Rated power & $\mathrm{P}_{\text {rated }}$ & $5.08 \mathrm{MW}$ \\
Nominal Torque & $T_{\text {rated }}$ & $4.02 \mathrm{MNm}$ \\
Rated mech. rotor speed & $\omega_{\text {rated }}$ & $1.25 \mathrm{rad} / \mathrm{s}$ \\
PMSG Pole Pairs pp & $\mathrm{p}_{\mathrm{p}}$ & 100 \\
Generator mom. of inertia & $\mathrm{J}_{g}$ & $534.166 \mathrm{kgm}^{2}$ \\
Turbine moment of inertia & $\mathrm{J}_{w}$ & $38.76 \times 10^{6} \mathrm{kgm}^{2}$ \\
Shaft stiffness & $\mathrm{k}_{w g}$ & $767.63 \times 10^{6} \mathrm{Nm} / \mathrm{rad}$ \\
Shaft damping & $\mathrm{d}_{w g}$ & $6.21 \times 10^{6} \mathrm{Nm} /(\mathrm{rad} / \mathrm{s})$ \\
Stator Resistance & $\mathrm{R}_{\mathrm{s}}$ & $50 \mathrm{~m} \Omega$ \\
Stator inductance (dq) & $\mathrm{L}_{\mathrm{sd}}=\mathrm{L}_{\mathrm{sq}}$ & $7.8 \mathrm{mH}$ \\
DC link voltage & $\mathrm{V}_{\mathrm{DC}}$ & $7.2 \mathrm{kV}$ \\
DC link capacitance & $\mathrm{C}_{\mathrm{DC}}$ & $50 \mathrm{mF}$
\end{tabular}

\section{ACKNOWLEDGMENT}

The work in this paper was supported by The University of Manchester and The Offshore Renewable Energy Catapult as part of the Electrical Infrastructure Research Hub.

\section{REFERENCES}

United Nations Framework Convention on Climate Change UNFCCC, "Race To Zero Campaign", Convention Official Website, [Online]. Available: https://unfccc.int/climate-action/race-to-zerocampaign. [Accessed: 05-Jun-2021].

J. Lee and F. Zhao, "Global Wind Report 2021," Global Wind Energy Council (GWEC), Report, 2021.

F. Blaabjerg and K. Ma, "Future on power electronics for wind turbine systems," IEEE J. Emerg. Sel. Top. Power Electron., vol. 1, no. 3, pp. 139-152, 2013.

J. Falck, C. Felgemacher, A. Rojko, M. Liserre, and P. Zacharias, "Reliability of Power Electronic Systems: An industry Perspective," IEEE Ind. Electron. Mag., vol. 12, no. 2, pp. 24-35, 2018.

M. Barnes, K. Brown, J. Carmona, D. Cevasco, M. Collu, C. Crabtree, S. Watson, "Technology Drivers in Windfarm Asset Management,", HOME Offshore project position paper, June 2018. DOI: 10.17861/20180718

S. Peyghami and F. Blaabjerg, "Availability Modeling in Power Converters Considering Components Aging," IEEE Trans. Energy Conversion, vol. 35, no. 4, pp. 1981-1984, 2020.

L. Alhmoud, "Reliability Improvement for a High-Power IGBT in Wind Energy Applications," IEEE Trans. Ind. Electron., vol. 65, no. 9, pp. 7129-7137, Sep. 2018.

C. Busca R. Teodorescu, F. Blaabjerg, S. Munk-Nielsen, L. Helle, T. Abeyasekera, and P. Rodriguez, "An overview of the reliability prediction related aspects of high power IGBTs in wind power applications," Microelectron. Reliab., vol. 51, no. 9-11, pp. 1903-1907, Sep. 2011.

K. Ma, M. Liserre, F. Blaabjerg, and T. Kerekes, "Thermal loading and lifetime estimation for power device considering mission profiles in wind power converter," IEEE Trans. Power Electron., vol. 30, no. 2, pp. 590-602, 2015.

D. Zhou, F. Blaabjerg, T. Franke, M. Tønnes, and M. Lau, "Comparison of Wind Power Converter Reliability with Low-Speed and Medium-Speed Permanent-Magnet Synchronous Generators," IEEE Trans. Ind. Electron., vol. 62, no. 10, pp. 6575-6584, 2015.

T. Lei, M. Barnes, S. Smith, S. H. Hur, A. Stock, and W. E. Leithead, "Using Improved Power Electronics Modeling and Turbine Control to Improve Wind Turbine Reliability," IEEE Trans. Energy Conversion, vol. 30, no. 3, pp. 1043-1051, 2015.

C. Chen, V. Pickert, M. Al-Greer, C. Jia, and C. Ng, "Localization 
and Detection of Bond Wire Faults in Multichip IGBT Power Modules," IEEE Trans. Power Electron., vol. 35, no. 8, pp. 78047815, 2020.

[13] A. Abuelnaga, M. Narimani, and A. S. Bahman, "A review on IGBT module failure modes and lifetime testing," IEEE Access, vol. 9, pp. 9643-9663, 2021.

[14] S. Yang, A. Bryant, P. Mawby, D. Xiang, Li Ran, and P. Tavner, “An Industry-Based Survey of Reliability in Power Electronic Converters," IEEE Trans. Ind. Appl., vol. 47, no. 3, pp. 1441-1451, May 2011.

[15] L. Yang, P. A. Agyakwa, and C. M. Johnson, "Physics-of-failure lifetime prediction models for wire bond interconnects in power electronic modules," IEEE Trans. Device Mater. Reliab., vol. 13, no. 1, pp. 9-17, 2013.

[16] M. Musallam, C. Yin, C. Bailey, and M. Johnson, "Mission ProfileBased Reliability Design and Real-Time Life Consumption Estimation in Power Electronics," IEEE Trans. Power Electron., vol. 30, no. 05, pp. 2601-2613, 2015.

[17] G. Zhang, D. Zhou, F. Blaabjerg, and J. Yang, "Mission profile resolution effects on lifetime estimation of doubly-fed induction generator power converter," Proc. - 2017 IEEE South. Power Electron. Conf. SPEC 2017, vol. 2018-Janua, pp. 1-6, 2018.

[18] A. Antonopoulos, S. D'Arco, M. Hernes, and D. Peftitsis, "Limitations and Guidelines for Damage Estimation Based on Lifetime Models for High-Power IGBTs in Realistic Application Conditions," IEEE J. Emerg. Sel. Top. Power Electron., vol. 9, no. 3, pp. 3598-3609, 2021.

[19] K. Fischer, K. Pelka, S. Puls, M.H. Poech, A. Mertens, A. Bartschat, B. Tegtmeier, C. Broer, and J. Wenske, "Exploring the Causes of Power-Converter Failure in Wind Turbines based on Comprehensive Field-Data and Damage Analysis," Energies, vol. 12, no. 4, 2019.

[20] K. Fischer, K. Pelka, A. Bartschat, B. Tegtmeier, D. Coronado, C. Broer, and J. Wenske, "Reliability of power converters in wind turbines: Exploratory analysis of failure and operating data from a worldwide turbine fleet," IEEE Trans. Power Electron., vol. 34, no. 7, pp. 6332-6344, 2019.

[21] S. Ye, D. Zhou, X. Yao, and F. Blaabjerg, "Component-Level Reliability Assessment of a Direct-Drive PMSG Wind Power Converter Considering Two Terms of Thermal Cycles and the Parameter Sensitivity Analysis," IEEE Trans. Power Electron., vol. 36, no. 9, pp. 10037-10050, 2021.

[22] J. Jonkman, S. Butterfield, W. Musial, and G. Scott, "Definition of a 5-MW Reference Wind Turbine for Offshore System Development," National Renewable Energy Laboratory NREL, Technical Report No. NREL/TP-500-38060, 2009.

[23] R. M. M. Slot and L. Svenningsen, "Consistent direct-drive version of the NREL 5MW turbine," WindEurope Conference, Hamburg, Germany 25-28, 2018.

[24] J. Carroll, A. McDonald, and D. McMillan, "Failure rate, repair time and unscheduled O\&M cost analysis of offshore wind turbines," Wind Energy, vol. 19, no. 6, pp. 1107-1119, 2016.

[25] J. Zhang, M. Cheng, and Z. Chen, "A novel stator interior permanent magnet generator for direct-drive wind turbines," IET Renew. Power Gener. Stevenage Vol. 1, Iss. 4, (Dec 2007) 203-210., no. 4, pp. 723$728,2007$.

[26] ABB, "Datasheet for IGBT Module ABB 5SNA 0400J650100," ABB Semicond., Datasheet, no. 5, pp. 1-9, 2016.

[27] K. Ma and F. Blaabjerg, "The impact of power switching devices on the thermal performance of a $10 \mathrm{MW}$ wind power NPC converter," Energies, vol. 5, no. 7, pp. 2559-2577, Jul. 2012.

[28] H. Ye, B. Yue, X. Li, and K. Strunz, "Modeling and simulation of multi-scale transients for PMSG-based wind power systems," Wind Energy, vol. 20, no. 8, pp. 1349-1364, Aug. 2017.

[29] S. M. Muyeen Md. Hasan Ali, R. Takahashi, T. Murata, J. Tamura, Y. Tomaki, A. Sakahara, and E. Sasano, "Comparative study on transient stability analysis of wind turbine generator system using different drive train models," IET Renew. Power Gener., vol. 1, no. 2, p. 131, 2007.

[30] J. W. Kolar and U. Drofenik, "A General Scheme for Calculating Switching and Conduction Losses of Power Semiconductors in Numerical Circuit Simulations of Power Electronic Systems," Int. Power Electron. Conf., 2005.

[31] B. Backlund, R. Schnell, U. Schlapbach, R. Fischer, and E. Tsyplakov, "Applying IGBTs," ABB Semicond., Application note 5SYA 2053-04, Lenzburg, Switzerland, 2008.
[32] A. Wintrich, U. Nicolai, W. Tursky, and T. Reimann, Application Manual Power Semiconductors, Semikron, ISLE Verlag, Ilmenau, 2015.

[33] K. Ma, Power Electronics for the Next Generation Wind Turbine Systems. Springer International Publishing, 2013.

[34] ASTM E1049, "Standard practices for cycle counting in fatigue analysis," ASTM Stand., vol. 85, no. Reapproved 2017, pp. 1-10, 2017.

[35] W. McKinney, "Data Structures for Statistical Computing in Python," in Proceedings of the 9th Python in Science Conference, 2010, pp. 56-61.

[36] A. Ahmedi et al., "Lifetime Estimation of IGBT Power Modules for Reliability Study of Wind Turbine Systems," in Proc. 10th Int. PEMD Conf., IET, 2020, pp. 729-734, doi: doi.org/10.1049/icp.2021.1111

[37] Oezkol E, Hartmann S. "Load-cycling capability of HiPak IGBT modules", ABB Semicond. , Application Note 5SYA2043-04, Zürich, Switzerland, 2014.

[38] V. Yaramasu and B. Wu, Model Predictive Control of Wind Energy Conversion Systems, John Wiley and Sons, 2016.

[39] M. Chinchilla, S. Arnaltes, and J. C. Burgos, "Control of permanentmagnet generators applied to variable-speed wind-energy systems connected to the grid," IEEE Trans. Energy Conversion, vol. 21, no. 1, pp. 130-135, 2006.

[40] D. Zhou, F. Blaabjerg, M. Lau, and M. Tonnes, "Thermal cycling overview of multi-megawatt two-level wind power converter at full grid code operation," IEEJ J. Ind. Appl., vol. 2, no. 4, pp. 173-182, 2013.

[41] N. J. Abbas, A. Wright, and L. Pao, "An Update to the National Renewable Energy Laboratory Baseline Wind Turbine Controller," J. Physics. Conf. Ser., vol. 1452, no. 1, pp. 1-14, 2020.

[42] Y. C. Gerstenmaier, W. Kiffe, and G. Wachutka, "Combination of thermal subsystems modeled by rapid circuit transformation," in 2007 13th International Workshop on Thermal Investigation of ICs and Systems (THERMINIC), 2007, pp. 115-120.

[43] Ma, K., He, N., Liserre, M., \& Blaabjerg, F. (2015). Frequencydomain thermal modeling and characterization of power semiconductor devices. IEEE Transactions on Power Electronics, 31(10), 7183-7193

[44] SEMIKRON, P16 Heatsinks Series, Datasheet, [Online]. Available: https://www.semikron.com/products/productclasses/accessories/heat sinks/detail/p-16-pm139410pm139450.html [Accessed: 22-May2021].

[45] ABB, "SEMIS Simulation Tool Three Phase 2-level VSC with IGBT User manual 5SYA 2105," (2020) ABB Semiconductors, User Manual, [Online] Available: https://www.hitachiabbpowergrids.com/offering/productandsystem/semiconductors/semis-models/semis4 [Accessed: 18July-2021].

\section{BIOGRAPHIES}

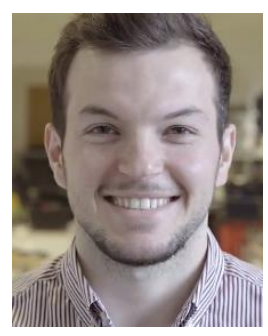

Arsim Ahmedi (S'17) earned his BSc degree in electrical engineering from University Ss Cyril and Methodius, Skopje, North Macedonia, in 2017, and his MSc in power electronics, machines and drives from The University of Manchester, Manchester, UK, in 2018, where he is currently, since 2019, pursuing a $\mathrm{PhD}$ which focuses on reliability modelling of power electronics in wind turbine systems. His research interests are in power electronics and grid integration of renewable energy sources.

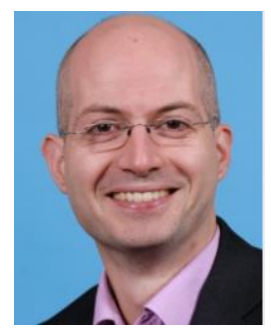

Mike Barnes (M'96-SM'07) received the B.Eng. degree in engineering and the Ph.D. degree from the University of Warwick, Warwick, U.K., in 1993 and 1998 , respectively. He is currently a Professor with the University of Manchester (formerly University of Manchester Institute of Science and Technology), Manchester, U.K. His principal research interests are in power electronics applied to power systems. He is a Fellow of the Institution of Engineering and Technology, U.K. 


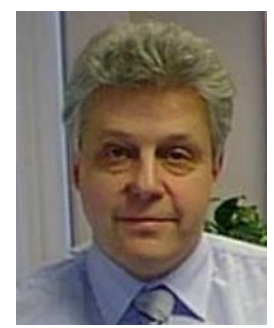

Victor Levi (S'89-M'91-SM'13) received the M.Sc. and $\mathrm{Ph} . \mathrm{D}$. degrees in electrical engineering from the University of Belgrade, Belgrade, Yugoslavia, in 1986 and 1991, respectively. From 1982 to 2001, he was with the University of Novi Sad, Novi Sad, Yugoslavia, where he was a Fulltime Professor in 2001. He was with the University of Manchester, Manchester, U.K. from 2001 to 2003, and then with United Utilities and Electricity North West, from 2003 to 2013. In 2013, he rejoined the University of

Manchester.

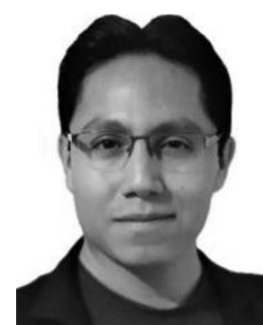

Jesús Carmona Sánchez received the B.E. degree in electromechanical engineering from the Instituto Tecnológico de Acapulco (ITA), Acapulco, México, in 2007, the M.Sc. degree in electrical engineering from Instituto Politécnico Nacional (IPN), Mexico City, Mexico, in 2010, and the Ph.D. degree from The University of Manchester, Manchester, U.K., in 2016. His main interests include modeling, control, and automated analysis of power electronic converters and renewable-smart energy systems. He is the Director of Jecasa, Ltd., and the recipient of the IEEE Energy Conversion Best Paper Award 2018-2019.

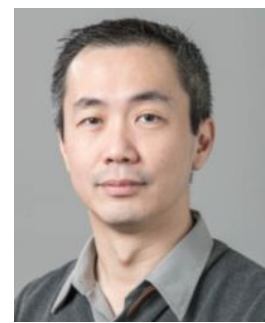

Chong Ng received the Ph.D. degree in electrical and electronics engineering from the University of Northumbria, Newcastle upon Tyne, U.K., in 2006. $\mathrm{He}$ is currently the Head of Applied Research of the Offshore Renewable Energy Catapult, Glasgow, U.K., and non-Exec Director of the TUS-ORE Catapult Research Centre, Beijing, China. He and his team focus on offshore renewable energy technologies and novel test and validation solutions research and developments, with project portfolio in excess of $£ 50$ mil and is the named inventor on multiple international patents.

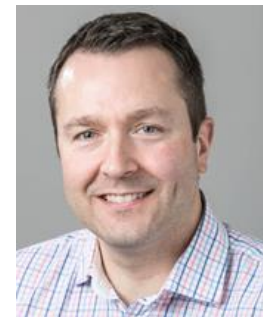

Paul Mckeever received the B.Eng. and M.Eng. (Hons.) degrees in electrical and electronic engineering from the University of Bradford, Bradford, U.K. He is currently the Head of Electrical Research with the Offshore Renewable Energy Catapult, U.K. Previously, he occupied the role of Head of Strategic Research and prior to that, he was the Project Coordinator for the OPTIMUS FP7 Project (prognostic condition monitoring), the Snapper FP7 Project, and Aqua-marine Power's Oyster Project (both wave energy converter projects). He is a member of the Durham Energy Institute's Industrial Advisory Board. He is also a member of the Institution of Engineering and Technology. He is also a Board Member of the European Association of Renewable Energy Research Centres, a Management Board Member of the European Energy Research Alliance Joint Program for Wind, and part of the Executive Committee for the European Technology and Innovation Platform for Wind. He also chairs the Industrial Advisory Board for the SuperGen ORE Hub. He is also a Chartered Engineer. 